\title{
Is routine induction of labour at term ever justified?
}

\author{
Linda Cardozo
}

\begin{abstract}
Balancing the risks of prolonged gestation against those of induced labour is difficult. Risks to the fetus increase slightly after $\mathbf{4 2}$ weeks' gestation but women having labour induced are more likely to have instrumental deliveries or babies with low Apgar scores. Since many women are now expressing a preference for minimal interference in childbirth the most acceptable management of post-term pregnancy seems to be increased fetal surveillance. Each case needs to be considered individually and it is important that the woman is involved in the decision to induce.
\end{abstract}

Although the World Health Organisation defines term as 37-42 completed weeks of pregnancy (259-294 days), most pregnant woman and many midwives think of term as the expected date of delivery. Women are given an expected delivery date that is calculated as 40 weeks ( 280 days) after the first day of the last menstrual bleed. But it is uncommon for the baby to arrive on that date, and women find it disappointing and sometimes worrying if delivery does not occur soon after this time. Perhaps we should reconsider whether it is necessary to give women a precise date on which they should expect their baby to arrive.

Accurate dating of pregnancy is important for other reasons, such as prenatal diagnosis and early identification of intrauterine growth retardation. In addition, ultrasonographic dating has been shown to reduce the incidence of truly prolonged pregnancy from about $10 \%$ to as low as $1 \%$. $^{1}$ Even among women who are sure of their dates the incidence of post-term pregnancy can be halved if an early ultrasound scan is performed. This is important as the outcome for women whose labour is induced for "uncertain postmaturity" is significantly worse than for those who have labour induced at 42 weeks' gestation. ${ }^{2}$

\section{Risks of post-term pregnancy}

Perinatal mortality is lowest at 40 weeks' gestation and does not increase until after 42 weeks, and then only slightly. But because some intrauterine deaths will always occur before 42 weeks it might seem sensible to deliver all babies at 42,41 , or even 40 weeks. The problem is induction of labour. Induced labour is longer and is associated with more instrumental deliveries, an increased risk of postpartum haemorrhage, and perhaps most importantly, a higher incidence of low Apgar scores than spontaneous labour. If the point of inducing labour is to reduce risks to the neonate then it may be failing. ${ }^{3}$

Before intravaginal prostaglandins were used regularly to ripen the cervix women having labour induced were more- likely to need caesarean section, which carries a risk of morbidity (and increased risk of mortality) for the mother. However, the Canadian multicentre post-term pregnancy trial group found that women allowed to go into labour spontaneously had a higher rate of caesarean section $(24.5 \%)$ than those who had labour induced $(21.2 \%)$ because of an increased incidence of fetal distress in the first stage. Unfortunately, the group did not define fetal distress, and the increased incidence may have been related to

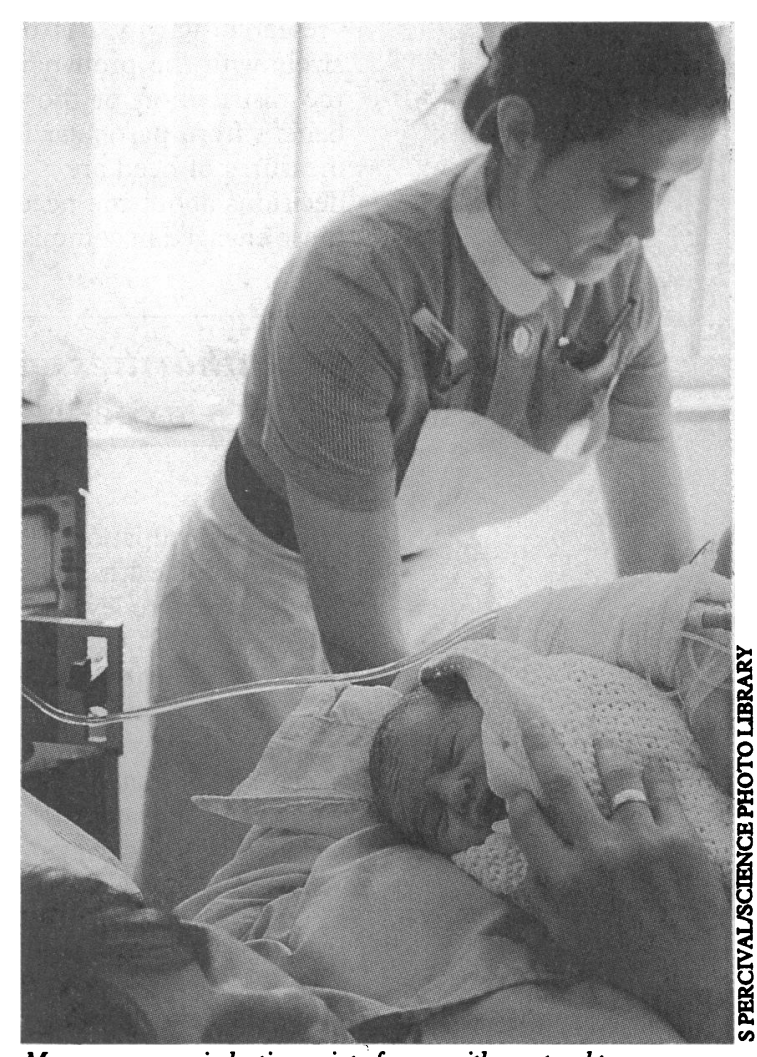

Many women see induction as interference with a natural process

the higher rate of meconium staining of the amniotic fluid in spontaneous labours, which is to be expected at a later gestation. There was no difference in the incidence of meconium aspiration, one of the greatest neonatal risks of prolonged pregnancy; nor were any other differences in perinatal outcome recorded. The intervention rate (instrument and operative delivery) in this large study of 3407 uncomplicated prolonged pregnancies, was $49 \%$ among women randomised to induction of labour and $51 \%$ for those who were monitored while awaiting spontaneous labour. In the United Kingdom many midwives, obstetricians, and mothers would consider this an unacceptably high level of intervention in an otherwise normal physiological process.

Women who go into spontaneous labour before their estimated date of delivery are fortunate as the risks to both mother and baby have been shown to increase as "term progresses." But there is no evidence that inducing labour improves the outcome for mother or baby. ${ }^{6}$ Many women see induction as interference with a natural process and it is one of the reasons why they write "birth plans."

\section{When to induce}

If routine induction of labour at term cannot be justified, when should intervention occur? Bergsjo et al suggested 43 weeks' gestation ${ }^{7}$ as induction at this time has a lower incidence of failure. ${ }^{8}$ However, a fixed cut off point seems unnecessarily prescriptive. Each case needs to be considered individually and timing of

\section{London SE5 9RS}

Linda Cardozo, consultant

obstetrician and gynaecologist

$B M F$ 1993;306:840-1 
delivery should be based on the woman's risk factors. Earlier induction of labour would obviously be preferable for a 40 year old primigravid woman with a long history of infertility, even after an uncomplicated pregnancy, whereas it may be inappropriate for a 25 year old multiparous woman.

The state of the cervix (Bishop's score) should also be considered. If delivery with an unfavourable cervix is thought essential it may be better to deliver by elective lower segment caesarean section under epidural block than to risk the need for an emergency caesarean section under general anaesthesia in the middle of the night. Emergency caesareans carry a much higher risk of morbidity and mortality to the mother and asphyxia to the baby. Recent data from King's College Hospital have shown an unacceptable incidence of unrecognised maternal morbidity associated with caesarean section and this may be compounded by the need for repeated operative delivery in subsequent pregnancies. ${ }^{9}$

\section{Alternatives to induction}

Is there anything we can do for women who go past term? Membrane stripping has been suggested to produce earlier spontaneous labour and have no complications, ${ }^{10}$ but it is also an intervention that many women would dislike. The best policy is probably to offer increased fetal surveillance after 42 weeks (or earlier if risk factors are present) and to terminate the pregnancy if adverse features occur. Pearce and McParland showed that the most sensitive measure in antenatal fetal surveillance is absence of end diastolic frequencies in the umbilical artery (assessed by Doppler ultrasonography). ${ }^{11}$ This predicted $91 \%$ of fetuses who became distressed in the first stage of labour, and combination with ultrasonographic estimation of the volume of amniotic fluid improved prediction to $100 \%$ with only a slight fall in specificity.

Perhaps the most important part of managing postterm pregnancy is involving the woman and her partner. The decision to induce or not should be discussed, and if possible the woman's views respected. I discuss induction of labour at 42 weeks' gestation in an otherwise uncomplicated pregnancy and offer it if the cervix is favourable and the woman keen to be delivered. I encourage women to have induction at 43 weeks' gestation because of the slightly increased risk to the baby thereafter. Unfortunately, there is no "right time" to induce nor any conclusive data on which to base a rational decision.

1 Boyd ME, Usher RH, McClem FH, Kramer MS. Obstetric consequences of postmaturity. Am Y Obstet Gynecol 1988;158:334-8.

2 Gibb DMF, Cardozo LD, Studd JWW, Cooper DJ. Prolonged pregnancy: is induction of labour indicated? A prospective study. Br $\mathcal{F}$ Obstet Gynaecol 1982;89:292-5.

3 Cardozo LD, Fysh J, Pearce JM. Prolonged pregnancy-the management debate. $B M \mathcal{F}$ 1986;293:1059-63.

4 Hannah ME, Hannah WJ, Hellmann J, Hewson S, Milner R, Willan A and the Canadian multicenter post-term pregnancy trial group. Induction of labor as Canadian multicenter post-term pregnancy trial group. Induction of labor as
compared with serial antenatal monitoring in post-term pregnancy. A compared with serial antenatal monitoring in post-term
randomised controlled trial. $N$ Engl $f$ Med 1992;326:1587-92.

5 Saunders N, Paterson C. Effect of gestational age on obstetric performance: when is "term" over? Lancet 1991;338:1190-2.

6 Chapatte O, Versi E. Gestational age and obstetric performance. Lancet 1992;339:122.

7 Bergsjo P, Gui-dan H, Su-qui Y, Zhi-zeng G, Bakketeig LS. Comparison of induced versus non-induced labor in post-term pregnancy. Acta Obstet Gynecol Scand 1989;68:683-7.

8 Augensen K, Bergsjo P, Eikeland T, Askrik K, Carlsen J. Randomised comparison of early versus late induction of labour in post-term pregnancy. BMf 1987;294:1192-5.

9 Kelleher C, Cardozo LD. Caesarean section-unrecognised morbidity. 7 Obstet Gynaecol (in press).

10 McColgin SW, Hampton HL, McCaul JF, Howard PR, Andrew ME, Morrison JC. Stripping membranes at term: can it safely reduce the incidence of post-term pregnancies? Obstet Gynecol 1990;76:678-80.

11 Pearce JM, McParland PJ. A comparison of Doppler flow velocity waveforms, amniotic fluid columns and non-stress test as a means of monitoring postdate pregnancies. Obstet Gynecol 1991;77:204-8.

(Accepted 28 January 1993)

\title{
Acute haemolysis induced by high dose ascorbic acid in glucose-6-phosphate dehydrogenase deficiency
}

\author{
D C Rees, H Kelsey, J D M Richards
}

High dose ascorbic acid can cause haemolysis in glucose6-phosphate dehydrogenase deficiency

\section{Department of Haematology, University College Hospital, London WC1E 6AU \\ D C Rees, registrar in haematology \\ $\mathrm{H}$ Kelsey, research fellow in haematology \\ JD M Richards, consultant in haematology}

Correspondence to: Dr Richards.

$B M 7$ 1993;306:841-2
The use of high dose ascorbic acid (vitamin C) has been advocated for a wide range of ailments for years. Such treatments are generally thought to have few adverse effects and are often self administered. We present a case illustrating the particular caution necessary in subjects at risk of glucose-6-phosphate dehydrogenase deficiency.

\section{Case report}

A 32 year old man born in Britain of Nigerian parents was admitted as an emergency case complaining of breathlessness, dark urine, and left subcostal pain radiating to the left shoulder. His history included malaria caught in Nigeria at the age of 11 and treated uneventfully with quinine. There was no family history of haemolytic crises and he had been healthy until December 1991, when he was found to have antibodies to HIV-1. There were no known risk factors for HIV infection. The exact source of the infection was unclear. His CD4 lymphocyte count was $0.35 \times 10^{\circ} / 1$. He had remained well until June 1992 , when he developed generalised lymphadenopathy and his doctors recommended that he should start zido- vudine. He had refused, however, and sought advice privately from a medically qualified nutritionist. An extensive nutritional screen was performed, including measurements of blood mineral, vitamin, and fatty acid concentrations. Among several abnormalities noted were low serum and red cell glutathione concentrations (red cell glutathione $1.1 \mathrm{mmol} / \mathrm{l}$ (normal $1 \cdot 6-2.8 \mathrm{mmol} / \mathrm{l})$, serum glutathione $3.2 \mu \mathrm{mol} / \mathrm{h}$ (normal 3.8-8.2 $\mu \mathrm{mol} / \mathrm{l}$ )).

He was prescribed a course of multivitamins, essential fatty acids, and glutathione supplements. He was also prescribed a course of high dose intravenous ascorbic acid, $40 \mathrm{~g}$ three times weekly, supplemented by $20-40 \mathrm{~g}$ ascorbic acid daily by mouth. This proceeded uneventfully for about a month with no obvious evidence of either haemolysis or regression of lymphadenopathy. The intravenous dose was increased to $80 \mathrm{~g}$, and next day the patient became breathless and feverish and noticed that his urine was black. His symptoms worsened over the next two days and he returned to the nutritionist.

Results of blood tests were: haemoglobin concentration $67 \mathrm{~g} /$, white cell count $12 \cdot 7 \times 10^{\circ} /$, platelet count $198 \times 10^{\circ} /$, reticulocyte count $15.6 \%$, bilirubin concen- 